Portland State University

PDXScholar

$12-20-2020$

\title{
Explicit Learning of Auditory Categories in Preschoolers With and Without Developmental Language Disorder
}

Lauren Casey

Portland State University

Follow this and additional works at: https://pdxscholar.library.pdx.edu/honorstheses

Part of the Speech and Hearing Science Commons, and the Speech Pathology and Audiology Commons

Let us know how access to this document benefits you.

\section{Recommended Citation}

Casey, Lauren, "Explicit Learning of Auditory Categories in Preschoolers With and Without Developmental Language Disorder" (2020). University Honors Theses. Paper 956.

https://doi.org/10.15760/honors.979

This Thesis is brought to you for free and open access. It has been accepted for inclusion in University Honors Theses by an authorized administrator of PDXScholar. Please contact us if we can make this document more accessible: pdxscholar@pdx.edu. 
Explicit Learning of Auditory Categories in Preschoolers With and Without Developmental Language Disorder

By

Lauren Casey

An undergraduate honors thesis submitted in partial fulfillment of the requirements for the degree of

Bachelor of Science

In

University Honors

And

Speech and Hearing Sciences

Thesis Advisor: Dr. Carolyn Quam Ph.D.

Portland State University

December 2020 


\begin{abstract}
This study is part of a broader study including Quam et al. (2020) and Yu (2020) with the aim of understanding how children with and without developmental language disorder learn language. With a better understanding of the underlying learning mechanisms affected in DLD, better interventions can be implemented. The current study investigates explicit language learning in preschoolers with and without developmental language disorder (DLD). This was done by observing sound discrimination and explicit sound-meaning mapping. One child with DLD and 29 children with typical language development (TLD) participated in this study. Inclusion in each group was determined by a hearing screening and standardized assessments of language and cognitive skills. Participants completed two computer-based tasks that assessed pitch and duration discrimination and explicit mapping of pitch- and duration- contrasted sounds to objects. This study showed that children with TLD were more successful in discriminating pitch than duration. Children with TLD were more successful in mapping pitch-contrasted sounds to meanings than they were with duration-contrasted sounds. There was a positive association between children's discrimination scores and their success in mapping sounds to meanings. The participant with DLD also showed more success in pitch-contrasted sound discrimination over duration-contrastes sound discrimination, and discrimination scores seemed to be associated with success in mapping sounds to meanings.
\end{abstract}

\title{
Introduction
}

Developmental Language Disorder (DLD) is a highly prevalent developmental disorder among children with its subgroup, Specific Language Impairment (SLI), at a prevalence of 7.4\% 
(Tomblin et al., 1997). Previously, all children demonstrating language disorders unrelated to a known biomedical reason and having a nonverbal IQ within the normal range, were categorized by researchers as having SLI, but debate surrounding this terminology came into the forefront of discussion in 2017 (Bishop et al., 2017; Volkers, 2018). The board of scientists and clinicians, Criteria and Terminology Applied to Language Impairments: Synthesizing the Evidence, CATALISE, who helped to redefine this terminology argued that inclusion criteria for SLI may have been too specific and prevented children with language disorders who didn't fit into this definition from getting access to the services they needed (Bishop et al.; Volkers, 2018). In addition to new terminology, this language disorder was also redefined to represent the overlap between disorders affecting language and other domains and to remove the noverbal IQ criteria used in identifying children with SLI (Bishop et al.; Volkers, 2018). The intention of this change in terminology was to ensure that all children with language disorders had access to therapy and other services, regardless of comorbidities that may have otherwise excluded them from receiving an SLI label (Bishop et al; Volkers, 2018).

Despite the recent terminological debate, there is a limited amount of research about this language disorder; therefore, knowledge about its etiologies and effective treatments is also limited. Two relevant etiologies argued to be the source of deficit for children with DLD include the auditory-processing impairment (Wright et al.,1997) and the Procedural Deficit Hypothesis (Ullman \& Pierpoint, 2005). The auditory-processing impairment account argues that it is difficulties in auditory processing that underlie the grammatical deficits found in children with DLD, including difficulties identifying speech sounds (Schwartz, Scheffler, \& Lopez, 2013) and discriminating between speakers (Dailey, Plante, \& Vance, 2013). The Procedural Deficit Hypothesis points to these language deficits being a result of abnormalities to the procedural 
memory system, with the declarative memory system being relatively spared (Ullman \& Pierpoint, 2005).

To further understand the etiology of DLD, this study will investigate how preschoolers with and without DLD we investigate learning of synthetic auditory categories as a means of testing different hypotheses regarding the source of language-learning impairments in DLD. Both sound discrimination and sound-meaning mapping will be assessed. Between Quam et al. (2020), the current study, and future research, a larger examination of the Procedural Deficit Hypothesis and the Auditory Processing Deficit Hypothesis and their impact on language learning can be observed.

This research aims to collect further data to advance the purposes of the broader study including Quam et al. (2020) and Yu (2020). A table indicating the differences and similarities between these studies and the current study is included (see Table 1). This research is innovative in the way it assesses language learning in children with DLD in a few key ways. The age of the participants included in this study are younger compared to other similar studies investigating DLD in young children. This is significant because of the difference in developmental stage and newly-emerging skills which could allow for greater sensitivity to auditory processing deficits and their correlation with sound-meaning mapping. In addition, the auditory stimuli used in this study are able to test for learning capacity rather than existing knowledge as the dimensions used in the stimuli, pitch and duration, are not used contrastively in English. This will eliminate extraneous factors that could influence a participants' performance- such as access to resources or parental input.

By investigating how children with and without DLD learn language dimensions and map sound stimuli to meanings, this study intends to contribute to and further current knowledge 
about the etiology of DLD and how best to provide intervention to children with it. In the study conducted by Quam et al., 2020, they found that children with TLD were more successful in mapping pitch categories to meaning than children with DLD and more successful in sound discrimination. There were also significant associations between sound discrimination and accuracy scores, particularly for pitch-contrasted sounds. All participants struggled in learning duration categories. To further investigate these findings, this study asked whether increased training and more differentiated auditory stimuli would boost duration-meaning mapping. An additional training block was added, the distance between stimuli was increased, and variability in the F2 was increased for the current study (Figure 1). The goal was to see if the results would replicate the previous finding that children overall are better able to discriminate, and map to meanings, pitch-contrasted sounds versus duration-contrasted sounds, or whether discrimination and learning of duration distinctions would be boosted by these methodological changes. Additionally, based on the findings from Quam et al. (2020) we hypothesize that there will be a positive association between discrimination and sound-meaning mapping scores. Based on the prior findings (Quam et al., 2020), we hypothesize that children with DLD will show more difficulty in both sound discrimination and sound-meaning mapping.

In observing explicit auditory categories (Quam et al., 2020), including with changes made to stimuli and training block length (current study); explicit visual categories (CITE OSHA POSTER); and implicit auditory and visual categories (Yu, 2020), , we hope to test the Procedural Deficit Hypothesis (PDH) and the auditory-processing deficit hypothesis. If the PDH is correct, children with DLD should show weaker sound-meaning mapping in the implicit auditory and visual conditions, due to domain-general difficulties with implicit learning. If the auditory-deficit hypothesis is correct, children with DLD should show weaker sound 
discrimination and mapping in both the implicit and explicit tasks, but no impairments in the visual experiments. If both hypotheses are true, and both types of impairments are interacting, then children with DLD may show impairments in all categories besides explicit visual. Any and all information gained in relation to the etiology and learning deficits in children with DLD will be contributing to the current literature in this area of study. This is critical information as it will guide future research, future practice for clinicians partnering with children with DLD, and standard practices used to teach language to children with DLD in schools and other settings.

\begin{tabular}{|l|l|l|l|l|l|}
\hline Study & $\begin{array}{l}\text { Quam et al. } \\
\text { (2020) }\end{array}$ & $\begin{array}{l}\text { Quam et al. } \\
\text { (in prep.) }\end{array}$ & Yu (2020) & Current Study & $\begin{array}{l}\text { Quam and } \\
\text { Franz (in } \\
\text { progress) }\end{array}$ \\
\hline Implicit/Explicit & Explicit & Implicit & Implicit & Explicit & Explicit \\
\hline Stimuli & $\begin{array}{l}\text { Sound } \\
\text { categories }\end{array}$ & $\begin{array}{l}\text { Sound } \\
\text { categories }\end{array}$ & $\begin{array}{l}\text { Sound and } \\
\text { visual } \\
\text { categories }\end{array}$ & $\begin{array}{l}\text { Sound } \\
\text { categories }\end{array}$ & $\begin{array}{l}\text { Visual } \\
\text { categories }\end{array}$ \\
\hline Instructions & $\begin{array}{l}\text { Children are } \\
\text { told the } \\
\text { monster } \\
\text { wants them } \\
\text { to "learn the } \\
\text { sounds for } \\
\text { her toys" }\end{array}$ & $\begin{array}{l}\text { Children are } \\
\text { told to give } \\
\text { the monster } \\
\text { his food or } \\
\text { drink as fast } \\
\text { as they can }\end{array}$ & $\begin{array}{l}\text { Children are } \\
\text { told to give the } \\
\text { monster his } \\
\text { food or drink } \\
\text { as fast as they } \\
\text { can }\end{array}$ & $\begin{array}{l}\text { Children are } \\
\text { told the } \\
\text { monster wants } \\
\text { them to "learn } \\
\text { the sounds for } \\
\text { her toys" }\end{array}$ & $\begin{array}{l}\text { Children are } \\
\text { told to learn } \\
\text { which type of } \\
\text { monster likes } \\
\text { which toy }\end{array}$ \\
\hline $\begin{array}{l}\text { Children's } \\
\text { responses }\end{array}$ & $\begin{array}{l}\text { Children's } \\
\text { responses } \\
\text { are direct } \\
\text { interpretatio } \\
\text { ns of sounds }\end{array}$ & $\begin{array}{l}\text { Children are } \\
\text { not required } \\
\text { to interpret } \\
\text { sounds, as } \\
\text { they can } \\
\text { wait and } \\
\text { respond } \\
\text { based on the } \\
\text { object that } \\
\text { appears on } \\
\text { the screen }\end{array}$ & $\begin{array}{l}\text { Children are } \\
\text { not required to } \\
\text { interpret } \\
\text { sounds, as they } \\
\text { can wait and } \\
\text { respond based } \\
\text { on the object } \\
\text { that appears on } \\
\text { the screen }\end{array}$ & $\begin{array}{l}\text { Children's } \\
\text { responses are } \\
\text { direct } \\
\text { interpretations } \\
\text { of sounds }\end{array}$ & $\begin{array}{l}\text { Children's } \\
\text { responses are } \\
\text { direct } \\
\text { interpretations } \\
\text { of sounds }\end{array}$ \\
\hline
\end{tabular}




\begin{tabular}{|l|l|l|l|l|l|}
\hline $\begin{array}{l}\text { Contingency/Fee } \\
\text { dback }\end{array}$ & $\begin{array}{l}\text { Feedback is } \\
\text { contingent } \\
\text { on the } \\
\text { child's } \\
\text { response } \\
\text { is provided } \\
\text { provided }\end{array}$ & $\begin{array}{l}\text { No feedback } \\
\text { No feedback is } \\
\text { the child's } \\
\text { response }\end{array}$ & $\begin{array}{l}\text { Feedback is } \\
\text { the child's } \\
\text { response }\end{array}$ & $\begin{array}{l}\text { Feedback is } \\
\text { contingent on }\end{array}$ \\
\hline $\begin{array}{l}\text { Table 1: Comparison of Task Designs in Four Experiments: Adapted from Yu } \\
\text { (2020) which was adapted from Quam et al. (in preparation) }\end{array}$ & \\
\hline
\end{tabular}

\section{Methodology}

\section{Participants:}

This study included 30 preschool children ages 4;0-5;11: 29 participants in the TLD group, and 1 participant in the DLD group. All participants were native English speakers and spoke English as their primary language since birth (see Table 2 for children's demographic information). Participants were recruited via public and private preschools and kindergartens in the Portland metro area. To approve their children's participation in this study, participants' parents or primary caregivers signed permission forms, and verbal consent was obtained from each participant throughout the study.

The inclusion criteria for the participants used in this study was the same as those used in Quam et al. (2020). All participants were assessed via a pure tone audiometric screening conducted at 1,000, 2,000, and 4,000 Hertz (Hz) at 20 Decibels (dB HL) in both ears individually. Cognition was measured using the Kaufman Assessment Battery for ChildrenSecond Edition (KABC-II; Kaufman and Kaufman, 2004) using the nonverbal subtests. All 
participants received a composite score of 75 or above on the nonverbal subtests of the KABC-II; therefore, indicating nonverbal cognition within the normal range. Additionally the Structured Photographic Expressive Language Test- Preschool: 2nd Addition (SPELT-P2;

Dawson et al., 2005) was administered to assess participants' expressive English skills. For this study, a score of 87 and above on the SPELT-P2 included participants in the TLD group, while a score of 86 and below included them in the DLD group. A cutoff score of 87 has been previously shown to provide the highest sensitivity and specificity (Greenslade et al., 2009). The Peabody Picture Vocabulary Test, Fourth Edition (PPVT-4; Dunn et al., 2007) was used in addition to the KABC-II and SPELT-P2 to gain an understanding of participants' broader language profile. See Table 2 for a summary of the participants' screening results.

During the recruitment stage, if a parent or teacher indicated concern about a participants' articulation skills, the Sounds-In-Words section of the Goldman-Fristoe Test of Articulation 2 (GFTA 2; Goldman et al., 2000) was administered. Children who scored below the cutoff score of 87 on the SPELT-P2 were re-scored on items that may have been missed due to articulatory limitations to examine if the score was still below the cutoff of 87 after accounting for these speech sound production skills. In the questionnaire administered to parents and caregivers, children reported to have a history of the following were excluded from the study: brain injuries, uncorrected vision concerns, and mobility restrictions that may affect a child's capacity to participate in the experiments. Seven participants were excluded due to various reasons including: not meeting cutoff criteria (4 participants), history of learning disability (1 participant), and lack of completion of assessments (2 participants). 


\begin{tabular}{|c|c|c|c|c|}
\hline & \multicolumn{3}{|c|}{ TLD } & \multirow[t]{2}{*}{ One Child with DLD } \\
\hline & Mean & SD & Range & \\
\hline Age (year;month) & $4 ; 9$ & 5 months & $4 ; 1-5 ; 11$ & $4 ; 6$ \\
\hline $\begin{array}{c}\text { Primary } \\
\text { Caregiver's } \\
\text { Education (years) }\end{array}$ & 16 & 1.6 & $12-18$ & 16 \\
\hline KABC-II & 114.8 & 11.6 & $91-138$ & 98 \\
\hline SPELT-P2 & 120 & 10.8 & $83-131$ & 83 \\
\hline PPVT-4 & 124.5 & 12.7 & $96-142$ & 107 \\
\hline
\end{tabular}

\section{Stimuli:}

Modified isolated vowel stimuli generated in Yu, 2020 were used in this study.

Synthesized isolated vowels mimicking $[\mathrm{u}]$ and [i] were used as the sound stimuli, generated via the KlattGrid speech synthesizer (Klatt and Klatt, 1990; Weenink, 2009) installed in Praat (Boersma and Weenink, 2008).

Within this experiment, there were two auditory cues: pitch-contrasted and duration-contrasted stimuli. Within each dimension, variations were used to distinguish the stimuli: high-pitch vs. low-pitch, and long-duration vs. short-duration. Each variation includes three sounds, resulting in 6 sounds for each dimension. In the dimension of pitch these include: high-pitch1, high-pitch2, high-pitch3, low-pitch1, low-pitch2, and low-pitch3. For the duration 
category these include: short-duration1, short-duration2, short-duration3, long-duration1, long-duration2, and long-duration3. The values for these stimuli are shown in Figure 1.

The pitch stimuli were distributed along a continuum characterized by semitones. Manipulation of the second-formant frequency (F2), made the pitch stimuli to mimic the vowel [u], and the duration stimuli were manipulated to mimic the vowel [i]. Quam et al. (2020) found that both children with DLD and children with TLD had more difficulty discriminating differences in duration than they did in pitch discrimination. To try to boost duration discrimination and duration-meaning mapping in the present study, the acoustic distances between categories (pitch and duration) were increased and variation in $\mathrm{f} 2$ of the vowels was added to further differentiate the sounds within-category, as within-category variability on an irrelevant dimension sometimes improves sound-category and word learning (e.g., Rost \& McMurray, 2009). The variation in F2 made some of the pitch-contrasted stimuli sound more like the vowel /i/ and some duration-contrast stimuli sound more like the vowel /u/. 


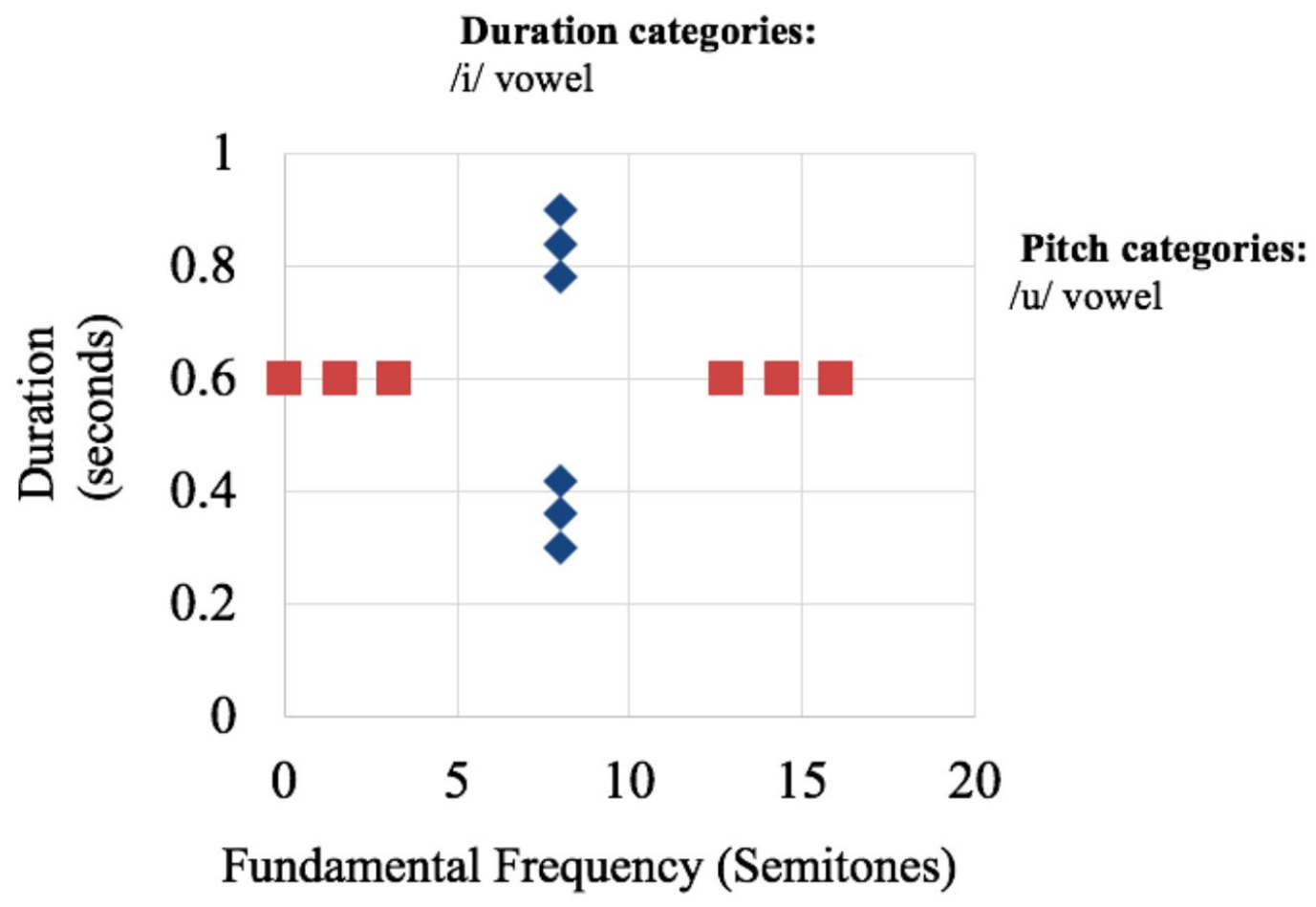

Figure 1: Auditory stimuli across a continuum using the Bark scale. Adapted from Yu, 2020.

Apparatus and Procedures:

The implicit (Yu, 2020) and explicit version of this study were created and conducted via the PsychoPy program (Peirce, 2007). Each participant completed four experiments via the computer-based PsychoPy program: one explicit sound-learning experiment, one explicit visual-learing experiment, one implicit sound-learning experiment, and one implicit visual-learning experiment.

To reduce contamination of learning, we arranged to avoid having one child finish two experiments in the same modality on one day (e.g., two visual or two auditory experiments on the same day). Due to incidental error though, five children in the TLD group completed two 
visual tasks on the same day, and one of them also completed two auditory tasks on the same day.

One explicit learning experiment, the test of explicit mapping of sounds to objects is reported in the current study. The two implicit learning experiments are reported in $(\mathrm{Yu}, 2020)$ and the explicit visual task (Quam \& Franz, in progress) will be reported in a future study.

Sound Discrimination Task:

The procedure used for this study is similar to that conducted in Quam et al. (2020). Participants were randomly assigned to learn pitch-contrasted or duration-contrasted sounds in the explicit-learning experiment; therefore, they learned sounds defined along the other dimension in the implicit-learning experiment. Prior to learning the sounds in either the explicit or implicit task, participants were asked to complete a sound-discrimination task. This task was intended to gather a baseline of their sensitivity to the prospective sound category they would be learning. Although only the explicit sound-meaning mapping task is analyzed here, the discrimination data collected prior to the implicit task are also included here (as in Quam et al., 2020).

For each sound discrimination task, participants heard 12 pairs of sounds, with each sound in each pair taken from a set of 6 sound stimuli (differentiated by pitch or duration) that make up the continuum. These sounds differed from each other acoustically by $0-5$ steps on the continuum, with one sound in each of the pairs being the endpoint of the continuum (See Figure 
1). Greater differentiation between auditory stimuli were used in this study than in Quam et al., 2020 to promote learning of duration and duration-meaning mapping. This resulted in 12 trials with sound pairs containing one sound at the endpoint of the continuum and the other identical or differing by $1-5$ acoustic steps.

In each of the 12 trials, participants were instructed to listen to two sounds and respond with "same" or "different", depending on if they thought the sounds were the same or not. The sounds in each trial were played with one second between. In each sound discrimniation task, the experimenter recorded the participants responses by pressing " $\mathrm{S}$ " when the child said the sounds were the "same" and "D" when the child said they were "different". Following the procedure outlined in Quam et al. (2020), the "same" “different" responses were converted to D' scores (see Statistical Design section for more information) which measured participant sensitivity to auditory differences across each cue (pitch or duration) and to see if changes in sensitivity were due to changes in the acoustic difference between sounds.

\section{Explicit Sound-Meaning-Mapping Task:}

The procedure used for this study was similar to that conducted in Quam et al. (2020). Following the sound-discrimination task, children participated in an explicit sound-meaning-mapping task in which they learned to map the same six sounds heard in the sound discrimination task to objects. 15 participants learned pitch-differentiated sounds while 15 learned duration-differentiated sounds. 
To familiarize the children with the task, experimenters first introduced Shelly (see Figure 2.1) as a "monster who speaks in a funny way". Participants were told that Shelly has "special sounds" for each toy and that it was their job to "listen really close to what she says" so they can learn the sounds for her toys and give them to her. Explicit instructions were given that the pictures of toys on the screen were the same as the images of toys attached with velcro to the computer's keyboard keys in front of them (see Figure 2). Children were asked to press the key that matched the toy on the screen. A few examples were given in which the experimenter told the participant, "if she wants this toy (points to toy on screen), show me which button you push (wait for participant to push one). Explicit feedback was given during the familiarization phase in the form of affirming statements such as "good job!" and "that's right!" following the similar procedure in Quam et al. (2020).

Before beginning the three testing blocks, children were reminded to listen carefully to Shelly and told that she would give them a smiley face if they choose the right toy and a frowny face if they chose the wrong toy. Additionally, they were told that if they choose the wrong toy it's okay "because the faces help you practice and learn so that you can give Shelley the toy she is asking for". Participants then attended to sounds over three 24 trial blocks (72 total trials) to determine what toy Shelly the monster wanted to play with. There is one additional trial block in the current study compared to that of Quam et al., 2020. This change was implemented with the intention of boosting duration-meaning mapping. Between each block, participants were offered the option to continue with the next part or take a wiggle/play break. If the experimenter noticed a child was alternating their key presses left and right, participants were gently reminded to “ really listen to Shelly before you make a choice. Make sure you don't just go back and forth like 
this (mime movement with your fingers). First, listen carefully to Shelly.” Upon completing these three trials, a final production task was given in which the experimenter asked if the child could "tell me what sound Shelly makes when she wants this toy (points to one). What sound does she make when she wants this one? (points to the other)". Responses were recorded via note taking and audio recording. While these acoustic analyses are not reported here, future studies will conduct them.

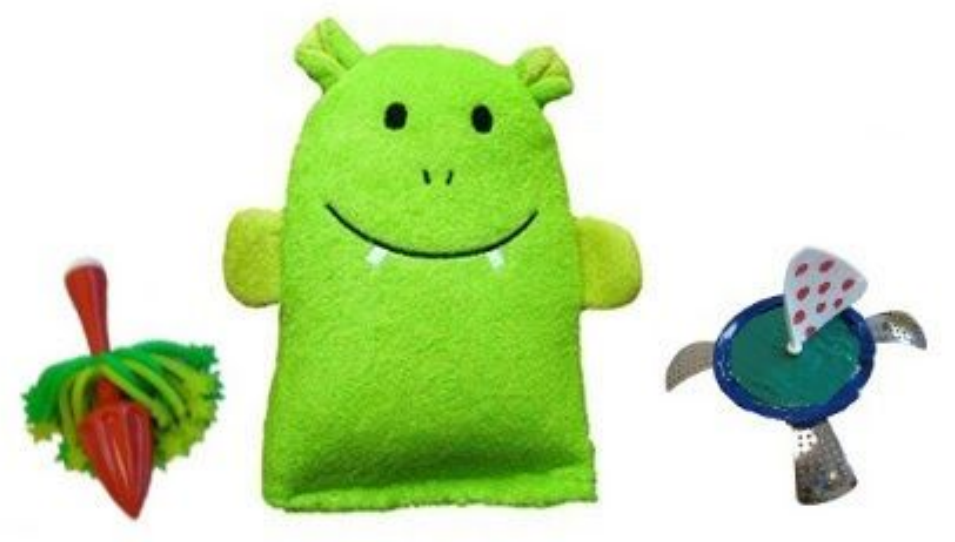

Figure 2: Sound-meaning-mapping task objects (toys) and Shelly the friendly monster. Adapted from Quam et al., 2020.

Statistical Design:

To analyze the data collected, we followed a similar procedure to that of Quam et al. (2020). The discrimination data, "same" and "different" responses were converted to D' scores. The sensitivity index (D' scores) was calculated by finding the difference between the z-scored 
hits $(\mathrm{H})$ and false alarms $(\mathrm{F})(\mathrm{z}(\mathrm{H})-\mathrm{z}(\mathrm{F}))$. The hits represented a response of "different" to a trial that included two sounds varying between 1-5 acoustic steps (i.e., a "Different" trial), and the false alarms represented a response of "different" to a trial including two sounds that had no acoustic difference (i.e., a "Same" trial).

Inferential statistics were then conducted for the discrimination task using a multivariate approach (MANOVA) for consistency with the broader set of studies (e.g., Quam et al., 2020, $\mathrm{Yu}, 2020)$. Type 1 error inflation was minimized using this approach as it minimizes the number of tests (Bodner, 2018). The statistical significance of all of the MAN(C)OVA tests was evaluated using Wilks' lambda due to its prevalent use in randomized trials (Bodner, 2018).

First, a MANOVA evaluated the impacts on D' scores of the within-subjects predictors cue (pitch, duration) and distance on the continuum (1-5). To minimize Type 1 error inflation, follow-up t-tests analyzing effects of distance on the continuum minimized the number of comparisons by only comparing adjacent distances. Bonferroni corrections for multiple comparisons were employed in follow-up tests of statistically significant multivariate effects when a variable had more than two levels. The variable of distance, for example, contains five levels and would therefore require this correction while the variable cue only has two levels so it would not. Variables included in these inferential statistics include cues (pitch and duration) and distances (1-5). Group (TLD and DLD) was not included as a variable due to only having one DLD participant. In future studies, the variable of group will be used as a between subject variable. Additionally, the variable of "first cue" indicating which task (pitch or duration) was completed first will be assessed to see if there were effects of task order on participant scores. Accuracy scores from the sound-meaning mapping task were also assessed via multivariate analyses of variance (MANOVAs) including the between subject variable of cue 
(pitch and duration), and the within subject variable of block (1-3). The variable of group (TLD and DLD) was again not included due to having only one participant with DLD, but future studies will include group as a between subject variable. Bonferroni corrections were employed for this test as well due to the variable of block containing more than two levels (3).

To analyze for any link between the sound discrimination and sound-meaning mapping tasks, multivariate analyses of covariance were used (MANCOVAs) with the covariate in these analyses being discriminations scores. These analyses helped to determine if discrimination scores were associated with later sound-meaning mapping for sounds differentiated on the same dimension. Cue (pitch and duration), block (1-3), and discrimination scores (operationalized by average across all distances) were the variables assessed in these analyses. We decided to simplify the discrimination scores in two ways. First, we computed the overall average of D' scores across all distances. Second, we used the discrimination scores at maximal distance (D5). This is the approach used in previous research (Quam et al., 2020, Yu, 2020).

\section{Results}

\section{Sound Discrimination:}

In analyzing the MANOVA for the sound discrimination task, the goal was to see if the results replicated the previous finding that children with TLD are better able to discriminate pitch-contrasted sounds versus duration-contrasted sounds. A MANOVA relies on normality of residuals. Visual inspection of residuals and the Shapiro-Wilk test of normality showed that any abnormality was not significant; therefore, it was appropriate to use MANOVA. . 
The MANOVA revealed a significant main effect of distance (Wilks' $\Lambda=.350, \mathrm{~F}(4,25)=$ 11.6, $\mathrm{p}<.001)$ meaning the distance between auditory stimuli impacted a child's success in discrimination. With the variable of distance containing more than two levels (5), the main effect was further investigated with Bonferroni-corrected t-tests. Two of these paired sample t-tests showed significance including D2 vs D3 $(\mathrm{t}(28)=3.145, \mathrm{p}=.002)$, and D3 vs D4 $(\mathrm{t}(28)=3.949, \mathrm{p}$ $<.001$ ) (see Table 3 for means).

The MANOVA revealed a significant main effect of cue $($ Wilks' $\Lambda=.784, F(1,28)=$ $7.708, \mathrm{p}=.010)$. Children were better able to discriminate pitch-contrasted sounds $(M=2.07, S D$ $=2.00)$ over duration-contrasted sounds $(M=3.28, S D=2.33)$. The MANOVA revealed a significant interaction between cue and distance $($ Wilks' $\Lambda=.468, F(4,25)=7.107, \mathrm{p}<.001)$. To examine the interaction between distance and cue (pitch and duration), adjacent distances on the continuum (D1 and D2, D2 and D3, etc) were compared via paired sample t-tests, for pitch and duration separately. See Figure 3 (pitch) and Figure 4 (duration) for the interaction of discrimination scores and distance across cues. For pitch, one of the paired sample t-tests showed significance, D2 vs D3 $(\mathrm{t}(28)=4.17, \mathrm{p}<.001)$ (see Table 3 for means and Figure 3 for the interaction between pitch and distance). For duration, one of the paired sample t-tests showed significance, D3 vs D4 $(\mathrm{t}(28)=4.37, \mathrm{p}<.001)$ (see Table 3 for means and Figure 4 for the interaction between duration and distance).

\section{Sound Discrimination for Participant with DLD:}

The participant with DLD showed more success discriminating pitch in D3 and D5. They were less successful than the mean scores of participants with TLD in D1, D2, and D4 (see Figure 3). In duration-discrimination, the participant with DLD showed more success in 
discriminating duration at D1, D2, and D3. They had a relatively equal score to the mean scores of participants with TLD at D4, and less success at D5 (see Figure 4). Overall, the child with DLD was more successful in discriminating pitch-contrasted sounds (mean=3.09) than duration-contrasted sounds (mean=2.47). Discrimination scores for the participant with DLD in pitch and duration fell within one standard deviation from the means of the participants with TLD across all distances with the exception of duration discrimination at D5 (within two SD).

\section{Pitch-Discrimination Scores}

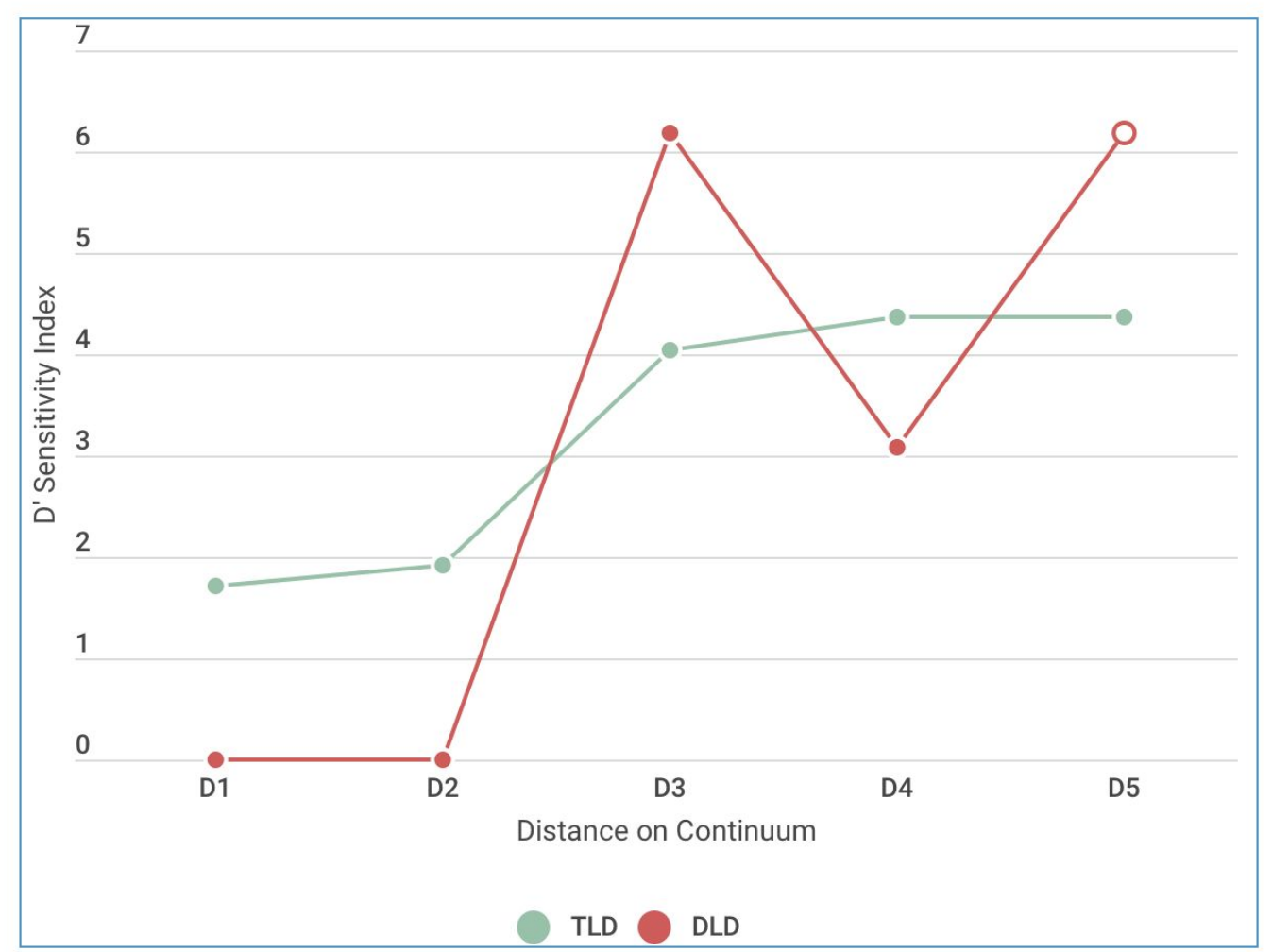

Figure 3: The interaction between Auditory D' scores for the cue of pitch and distance on the continuum (1-5) is illustrated. The participant with DLD's scores are shown in comparison. 


\section{Duration-Discrimination Scores}

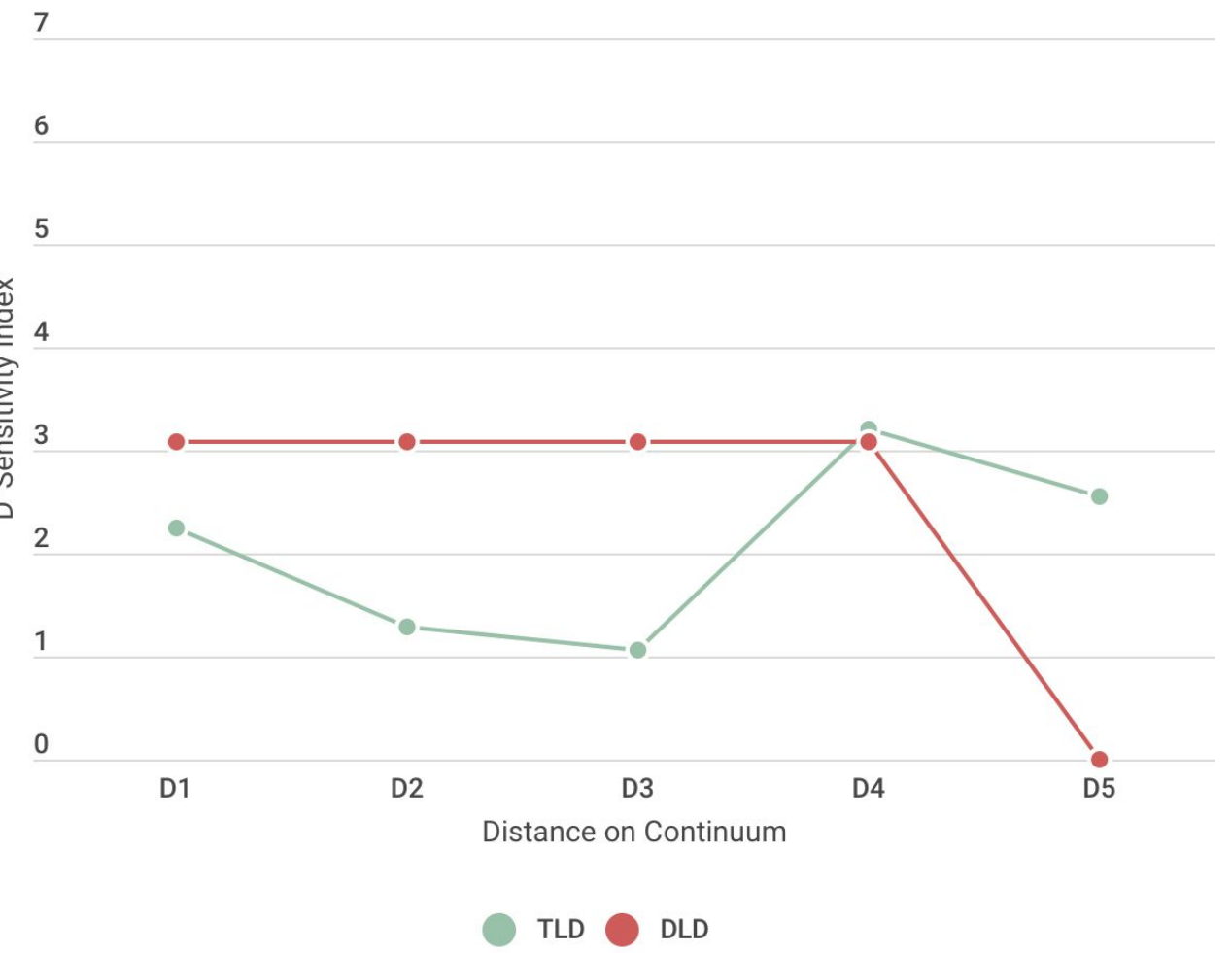

Figure 4: The interaction between Auditory D' scores for the cue of duration and distance on the continuum (1-5) is illustrated. The participant with DLD's scores are shown in comparison.

\begin{tabular}{|c|c|c|c|c|c|c|}
\hline Distance & & 1 & 2 & 3 & 4 & 5 \\
\hline $\begin{array}{c}\text { D-prime } \\
\text { Scores } \\
\text { Overall } \\
\text { (TLD) }\end{array}$ & Mean & 1.971 & 1.598 & 2.557 & 3.783 & 3.463 \\
& SD & 2.332 & 2.242 & 2.157 & 2.005 & 1.921 \\
\hline D-prime & Mean & 1.705 & 1.918 & 4.049 & 4.369 & 4.369 \\
\hline
\end{tabular}




\begin{tabular}{|c|c|c|c|c|c|c|}
\hline $\begin{array}{c}\text { scores for } \\
\text { Pitch (TLD) }\end{array}$ & SD & $\begin{array}{c}2.687 \\
\text { Range }\end{array}$ & $\begin{array}{c}2.910 \\
(-3.09-6.18)\end{array}$ & $\begin{array}{c}2.990 \\
(-3.09-6.18)\end{array}$ & $\begin{array}{c}2.803 \\
(-3.09-6.18)\end{array}$ & $\begin{array}{c}(-3.09-6.18) \\
(-3.09-6.18)\end{array}$ \\
\hline $\begin{array}{c}\text { D-prime } \\
\text { scores for } \\
\text { Duration } \\
\text { (TLD) }\end{array}$ & Mean & 2.238 & 1.279 & 1.066 & 3.197 & 2.558 \\
\hline $\begin{array}{c}\text { D-prime } \\
\text { scores for } \\
\text { Pitch (DLD) }\end{array}$ & Mean & 2.727 & 2.922 & 2.515 & 2.405 & 2.346 \\
\hline $\begin{array}{c}\text { D-prime } \\
\text { scores for } \\
\text { Duration } \\
\text { (DLD) }\end{array}$ & Mean & 3.09 & 3.09 & 3.09 & 3.09 & $(-09-69-6.18)$ \\
\hline
\end{tabular}

Table 3: Auditory d-prime scores across five distances for children with TLD (mean, standard deviation, and range) and one child with DLD (mean). Partially adapted from Yu (2020).

\section{Sound-Meaning Mapping Accuracy:}

In conducting the MANOVA for the sound-meaning-mapping task, the goal was to determine whether the increased training and more differentiated auditory stimuli (compared to Quam et al., 2020) would boost duration-meaning mapping, or whether it would still be at chance, and much lower than pitch-meaning mapping. While normality of residuals is an assumption of the MANOVA approach, it was violated for this dataset. Normality was determined by visual inspection of residuals and the Shapiro-Wilk test of normality. Significant non-normality was observed overall $(\mathrm{W}=.865, \mathrm{p}=.002)$. Upon visual inspection, the distribution of the residuals was not right or left skewed (instead it appeared to be bimodal), so it was not appropriate to perform a log or square transform on the data. For this reason, the MANOVA approach was still employed. Thus, we plan to employ non-parametric tests, such as permutation tests, in addition to parametric t-tests, to investigate any significant effects or interactions. 
Variables included in the MANOVA included the within subject variable of block (1-3) and the between subject variable of cue (pitch or duration). A significant main effect for cue was found $(\mathrm{F}=12.356, \mathrm{p}=.002)$. These results show that pitch-contrasted sounds were more successfully mapped to objects over duration-contrasted sounds by participants with TLD (see Table 4 for means and standard deviations). There were no significant effects or interactions with block.

Sound-Meaning Mapping Accuracy for Participant with DLD:

As explicit duration was the only cue assessed in this study for the participant with DLD, results are only reported for duration (implicit pitch assessed in $\mathrm{Yu}, 2020$ ). The participant with DLD showed slightly lower scores for duration discrimination compared to the mean scores of participants with TLD (see table 4).

\begin{tabular}{|c|c|c|c|}
\hline Cue & Mean & Standard Deviation & $\begin{array}{l}\text { One Participant with } \\
\text { DLD }\end{array}$ \\
\hline Pitch & .75 & .18 & - \\
\hline Duration & .54 & .13 & .47 \\
\hline
\end{tabular}

Table 4: Main effect for cue illustrated by mean and standard deviation for pitch and duration. Accuracy scores reported individually for one child with DLD.

\section{Linking Model:}

In analyzing the relationship between discrimination scores and accuracy scores, the goal is to identify if there is a positive association between discrimination and sound-meaning mapping. Based on previous research, it is anticipated that there will be a positive association 
between the two (Quam et al., 2020). If discrimination influences sound-meaning mapping, then a weak discrimination score would lead to difficulty in sound-meaning mapping as well. In order to include the discrimination scores as a continuous predictor variable, simplification was required ( see Stastical Design). For the linking model, the covariate of discrimination scores was added, so a MANCOVA approach was employed.

Two models were run to analyze the link between sound discrimination and accuracy scores, one including average D' scores as the covariate, and another with D' scores at D5. Each model included the within subject variable of block (1-3), the between subject variable of cue (pitch or duration), the covariate of Discrimination scores (distance five or average D'), and the dependent variable of accuracy scores from the sound-meaning mapping task. With the covariate of D' scores at distance five, there was a significant effect of discrimination $(\mathrm{F}(1,25)=6.566, \mathrm{p}=$ .017) meaning that discrimination scores were positively associated with accuracy scores. The previously significant main effect of cue was no longer significant with the added covariate of D' at D5 $(\mathrm{F}(1,25)=.364, \mathrm{p}=.552)$, which could indicate that the main effect of cue that was significant in the original model, which did not take discrimination into account, was actually driven by differences in discrimination for pitch vs. duration (but this is speculative). There was also a marginal interaction between cue and distance $5(\mathrm{~F}(1,25)=3.702, \mathrm{p}=.066)$, which suggests the previously reported finding, of a stronger link between discrimination and mapping for pitch than for duration (Quam et al., 2020), might be replicated with a larger sample size (but this is also speculative and needs further analysis).

When the covariate of average D' scores was added, the previous significant effect of cue was no longer significant $(F(1,25)=.077, p=.783)$. Again, this suggests that effects of cue can likely be attributed to differences in discrimination. However, in this case, the effect of 
discrimination was not significant in this model either $(F(1,25)=1.814, p=.190)$, and neither was the interaction of cue and discrimination $(F(1,25)=2.531, \mathrm{p}=.124)$.

\section{Participant with DLD}

In evaluating the linking model scatter plot (Figure 5), the child with DLD seemed to fall relatively close to the linear regression line $(0, .47)$. While their score was on the low end compared to the group, they were also on the low end for discrimination, so their scores seemed to reflect the association in the TLD group between discrimination and mapping accuracy. This suggests that if more children with DLD were tested, the association found previously by Quam et al. (2020), and the low discrimination and mapping scores for children with DLD, would be likely to be replicated. 


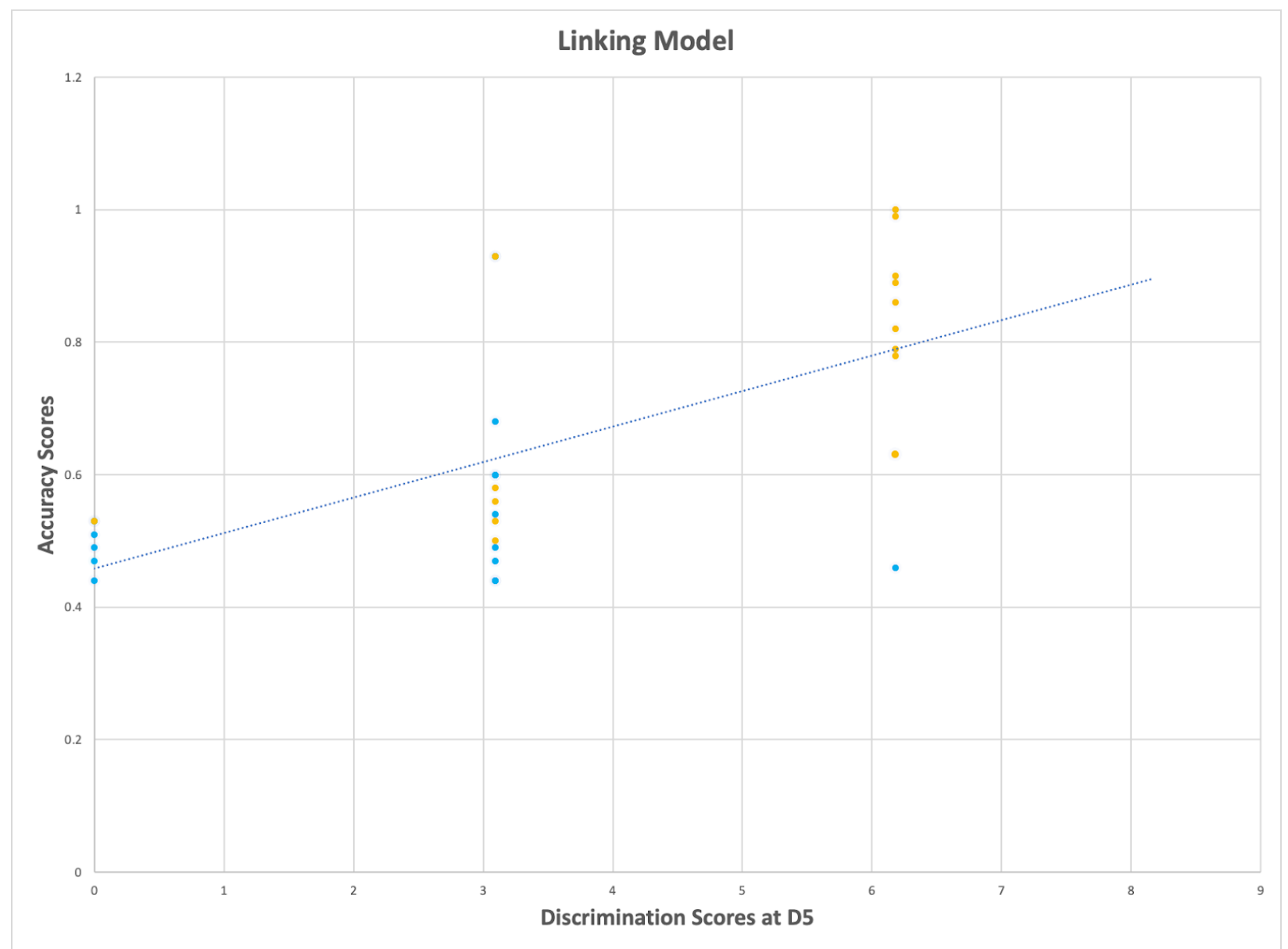

Figure 5: Scatter plot comparing D' scores at D5 and accuracy scores for all participants (with and without DLD). Light blue points represent participants who discriminated duration-contrasted sounds. Orange points represent participants who discriminated pitch-contrasted sounds. The participant with DLD is shown in blue (duration) at $(0,0.47)$.

\section{Discussion}

In this study we examined explicit learning of auditory categories in preschoolers with and without Developmental Language Disorder. Our primary goal was to better understand what underlying learning mechanisms may contribute to language-learning impairments in DLD. This study only included one participant with DLD, so the conclusions drawn are primarily in 
response to the results from the children with Typical Language Development (TLD). Despite this, tentative conclusions about the performance of the child with DLD are provided. This study asked three primary questions including: "Are children with TLD able to better discriminate pitch than duration-contrasted sounds?"; "Are children more successful in mapping pitch-contrasted sounds to objects than duration-contrasted sounds?"; "Do discrimination scores indicate potential success in the sound-meaning-mapping task?". These same questions were asked for the child with DLD in addition to how the participant with DLD's performance will compare to the TLD group.

The MANOVA analyzing sound discrimiation showed that yes, children were more successful in discriminating pitch over duration-contrasted sounds. This is a replication of what was found in Quam et al., 2020 and Yu, 2020. Similarly to the participants with TLD, the participant with DLD showed greater success in pitch-contrasted sound discrimination than duration-contrasted sound discrimination. Discrimination scores for the participant with DLD in pitch and duration fell within one standard deviation from the means of the participants with TLD across all distances with the exception of duration discrimination at D5 (within two SD). The MANOVA analyzing sound-meaning-mapping also showed that children with TLD were more successful in mapping pitch-contrasted sounds to objects over duration-contrasted sounds. Both pitch and duration are not used contrastively in English, but are used for other functions, so it would be expected for children to have comparable performance learning both (Dietrich, Swingley, Wereker, 2007; Quam \& Swingley, 2010). Despite this, the current experiment as well as the others in this study have shown more success in pitch every time (Quam et al., 2020; Yu, 2020). These results replicated what was found in Quam et al., 2020 and Yu, 2020 with children showing more success in pitch-contrasted sound-meaning-mapping. There was a link between 
discrimination scores operationalized by distance five (D5) and accuracy scores that was also found in Quam et al, 2020, but not in Yu, 2020. This evidence points to the need for further research with more a more robust number of participants, with and without DLD. Similarly to the children with TLD, this participant's low discrimination score appeared to be an indicator of low accuracy scores (Figure 5). The link between sound discrimination and accuracy could be considered as evidence supporting the auditory-deficit hypothesis stating that auditory processing impairments are an underlying factor in grammatical errors present in children with DLD (Dailey, Plante, \& Vance, 2013; Schwartz, Scheffler, \& Lopez, 2013; Wright et al., 1997). This is a tentative conclusion to draw considering there was only one participant with DLD included in this study.

\section{Future Research:}

To contribute to the current literature and add on to what was found in this study, we propose that future research eliminate the cue of duration. The contrastive element of duration has not shown to be learnable for children with TLD, so it cannot be used as a baseline for learning. Even with the modifications added to the auditory stimuli in this study (e.g., the introduction of variability in F2) and the introduction of additional training blocks, duration was still challenging. The variable of group was not included in this study due to only having one participant with DLD, but in future studies the between subject variable of group will be added. Additionally, the variable of "first cue" indicating which task was completed first will be assessed to see if task order impact participant scores.

A tentative plan for future research would be to continue to test children's learning of explicit visual categories, implicit auditory pitch (removing the variable of duration), and 
implicit visual categories. Explicit auditory categories will not be included due to the replication of results between this study and Quam et al., 2020 and because the children have not been successful at learning duration-contrasted stimuli.

\section{Conclusion}

To summarize, the current study of sound discrimination and explicit sound-meaning mapping showed that overall children with and without DLD discriminated and mapped pitch-contrasted sounds more successfully than duration-contrasted sounds. There was a positive association between sound discrimination and accuracy for all participants. If the link between sound discrimination and sound-meaning-mapping holds in future research, this could suggest that intervention for children with DLD may need to include targeting auditory processing in order to strengthen it. Future research with a larger number of participants with DLD is needed before drawing more concrete conclusions about the etiology of Developmental Language Disorder. 


\section{Works Cited}

Bishop, D. V. (2017). Why is it so hard to reach agreement on terminology? The case of developmental language disorder (DLD). International journal of language \& communication disorders, 52(6), 671-680.

Bodner, T.E. (2018). Estimating and testing for differential treatment effects on outcomes when the outcome variances differ. Psychological Methods, 23, 125-37.

Boersma, P. and Weenink, D. (2008). Praat: Doing phonetics by computer (Version 5.0.30) [Computer program].

Dailey, N. S., Plante, E., \& Vance, R. (2013). Talker discrimination in preschool children with and without specific language impairment. Journal of Communication Disorders, 46(4), 330-337.

Dawson, J. I., Stout, C., Eyer, J., Tattersall, P. J., Fonkalsrud, J., Croley, K., and Janelle Publications (Firm) (2005). SPELT-P 2: Structured Photographic Expressive Language Test. Janelle Publications, DeKalb, Ill.

Dietrich, C., Swingley, D., \& Werker, J. F. (2007). Native language governs interpretation of salient speech sound differences at 18 months. Proceedings of the National Academy of Sciences, 104(41), 16027-16031.

Dunn, L. M., Dunn, D. M., and Pearson Assessments (2007). PPVT-4: Peabody Picture Vocabulary Test. Pearson Assessments, Minneapolis, MN.

Goldman, R., Fristoe, M., and American Guidance Service (Firm) (2000). Goldman Fristoe 2 Test of Articulation. American Guidance Service, Circle Pines, MN (Publishers' Bldg., Circle Pines 55014-1796).

Greenslade, K. J., Plante, E., \& Vance, R. (2009). The diagnostic accuracy and construct validity of the Structured Photographic Expressive Language Test-Preschool. Language, Speech, and Hearing Services in Schools.

Kaufman, A. S., \& Kaufman, N. L. (2004). Kaufman test of educational achievement-comprehensive form. American Guidance Service.

Klatt, D. H., \& Klatt, L. C. (1990). Analysis, synthesis, and perception of voice quality variations among female and male talkers. the Journal of the Acoustical Society of America, 87(2), 820-857.

Peirce, J. W. (2007). PsychoPy-Psychophysics software in Python. Journal of neuroscience methods., 162(1):8. 
Quam, C., Cardinal, H., Gallegos, C., \& Bodner, T. (2020). Sound discrimination and explicit mapping of sounds to meanings in preschoolers with and without developmental language disorder. International journal of speech-language pathology, 1-12.

Quam, C., \& Swingley, D. (2010). Phonological knowledge guides 2-year-olds' and adults' interpretation of salient pitch contours in word learning. Journal of memory and language, 62(2), 135-150.

Schwartz, R. G., Scheffler, F. L., \& Lopez, K. (2013). Speech perception and lexical effects in specific language impairment. Clinical linguistics \& phonetics, 27(5), 339-354.

Tallal, Paula, et al. "Language comprehension in language-learning impaired children improved with acoustically modified speech." Science 271.5245 (1996): 81-84.

Tomblin, J. B., Records, N. L., Buckwalter, P., Zhang, X., Smith, E., \& O’Brien, M. (1997). Prevalence of specific language impairment in kindergarten children. Journal of speech, language, and hearing research, 40(6), 1245-1260.

Ullman, M. T., \& Pierpont, E. I. (2005). Specific language impairment is not specific to language: The procedural deficit hypothesis. Cortex, 41(3), 399-433.

Volkers, N. (2018). Diverging Views on Language Disorders: Researchers debate whether the label "developmental language disorder" should replace "specific language impairment.”. The ASHA Leader, 23(12), 44-53.

Weenink, D. (2009). The KlattGrid speech synthesizer. In Tenth Annual Conference of the International Speech Communication Association.

Wright, B. A., Lombardino, L. J., King, W. M., Puranik, C. S., Leonard, C. M., \& Merzenich, M. M. (1997). Deficits in auditory temporal and spectral resolution in language-impaired children. Nature, 387(6629), 176-178.

Yu, W. (2020). Implicit Learning of Children with and without Developmental Language Disorder across Auditory and Visual Categories (Master's Thesis, Portland State University, Portland, Oregon). 